\title{
Preservation of Posterior Mitral Leaflet in Mitral Valve Replacement: Effect on Left Ventricular Geometry with Immediate Outcome.
}

\author{
A K M Manzurul Alam, Monzil Ahmed, ,Istiaq Ahmed, Mamun Hossain, Mohashin Reza, S.M. Parvez \\ Ahmed, Mizanur Rahman, Saiful Islam \\ Department of Cardiac Surgery, NICVD, Dhaka
}

\begin{abstract}
:
Keywords:

Mitral valve,

Left

ventricular

function.

Bcakground: Preservation of the posterior mitral leaflet and subvalvular structures during mitral valve replacement (MVR) preserve left ventricular geometry and function. We evaluated the effect of preservation of subvalvular structures during mitral valve replacement on LV ejection fraction (LVEF).

Methods: Total 60 patients were taken and then grouped into group A and group B. Group A include patients of MVR with preservation of posterior leaflet and subvalvular structure, Group B without preservation of subvalvular structures. All patients were evaluated before operation, at discharge, and at 3 months follow-up. Left ventricular function was assessed by ventricular ejection fraction (LVEF).

Results: Preoperative LV ejection fraction was $58.3 \pm 11.0 \%$ and $56.6 \pm 8.4 \%$ in Group A and Group B respectively. Post-operative mean LVEF at discharge was found $44.2 \pm 5.1 \%$ in group A and $37.3 \pm 4.8 \%$ in group B. Observation at three months follow-up showed that mean LVEF was $49.0 \pm 4.7 \%$ in group A and $39.6 \pm 4.7 \%$ in group $B$.

Conclusion: Left ventricular function is better maintained when MVR is done preserving posterior leaflet and subvalvular structure.
\end{abstract}

(Cardiovasc. j. 2018; 11(1): 39-41)

Introduction:

Repair of the mitral valve Sub-valvular apparatus preservation after mitral valve replacement is not a new concept, yet to date there has been no quantification of its clinical effectiveness as procedure and no consensus as to which surgical preservation technique should be adopted to achieve the best immediate and midterm clinical outcomes. ${ }^{1}$ Lilehei and associates suggested that preservation of posterior mitral valve leaflet and subvalvular apparatus preserve left ventricular functions. ${ }^{2}$ In a study in National institute of cardio vascular diseases, Dhaka showed that there was significant higher incidence of developing low cardiac output and congestive heart failure in conventional mitral replacement group than patients where subvalvular structures are preserved. ${ }^{3}$ His study was designed to compare the left ventricular function after conventional MVR and MVR with preservation of poster leaflet and subvalvular apparatus.

\section{Methods:}

This prospective randomized study carried out in Department of Cardiac Surgery, National Institute of Cardiovascular Disease (NICVD), Dhaka, Bangladesh during the period of July 2007 to June 2009 with the permission of academic council of this institute among the adult patients of mitral valve disease who had gone for mitral valve replacement. Total 60 patients are taken and then grouped into group A and group B. Group A include patients of MVR with preservation of posterior leaflet and subvalvular structure Group B only MVR. Data were collected in data collection sheet and analyzed with statistical package for social science.

\section{Surgical techniques:}

Under general anesthesia the chest was opened with standard mediansternotomy CPB was established with aortic wand bi-cavalcannulation. 
The heart was arrested by ante-grade cold $\left(4^{0} \mathrm{C}\right)$ blood cardioplegic solution under moderate hypothermia. After atritomy the mitral valve was examined and excised. In group A patients anterior mitral leaflet was incised at its base, 2 $\mathrm{cm}$ from the annulus. The posterior leaflet was imbricated to the annulus. Alternatively, the leaflet was incised from edge to base at two or three points in between the scallops. In chronic mitral regurgitation (MR) posterior leaflet was left in situ. In Group B patients both the leaflets (anterior and posterior leaflets) were excised. Then mitral valve replacement was done. After the operation the patients were shifted to the ICU. Anticoagulants and other drugs were prescribed as per protocol of the institute.

\section{Follow-up and Evaluation:}

All patients were evaluated with transthoracic echocardiography before operation, at discharge, and at 3 months follow-up. Left ventricular function was assessed by ventricular ejection fraction (LVEF).

\section{Results:}

A total of 62 patients who underwent MVR for mitral stenosis with or without mitral regurgitation, were included in the study. Of which 34 patients underwent MVR with preservation of posterior mitral valve leaflet and subvalvular apparatus was considered group A and 28 patients under went MVR was considered group B. In this study it Aortic cross clump time required was $94.9 \pm 26.7$ minutes for group A and 104.6 \pm 43.5 minutes for Group B. There was no significant difference of cross clump time between two groups. Low cardiac output syndrome (LOS) was only developed in $2.9 \%$ of group A, but not found in group B. There was no significant difference of preoperative LVEF (58.3 $\pm 11.0 \%$ vs. $56.6 \pm 8.4 \%$ ) between group A and group B. It was observed that the post-operative mean LVEF at discharge was found $44.2 \pm 5.1$ percent in group $\mathrm{A}$ and $37.3 \pm 4.8$ percent in group B. This shows that postoperative LVEF was better preserved in group A compared to groupB. Observation at three months follow-up showed that mean LVEF was $49.0 \pm 4.7 \%$ in group A and $39.6 \pm 4.7 \%$ in group B. Although there was rise of LVEF in group -A, it did not reach its preoperative level. On the other hand LVEF of group B did not change significantly. To compare the LVEF preoperative, postoperative at discharge and postoperative after 3 months follow-up and found there was significant fall of LVEF from preoperative to postoperative at discharge in both groups. After three months fall of LVEF persisted and did not rise up to its preoperative level.

level, although from discharge the rise was more in group A than group B. but within group compared to preoperative to postoperative at the discharge and after three months follow-up in both groups. The reduction rate was higher in group B compared to group A.

Table-I

Comparison of left ventricular ejection fraction of patients with in groups.

\begin{tabular}{|c|c|c|c|c|c|c|}
\hline Group & $\begin{array}{c}\text { Preoperative } \\
\text { LVEF(\%) } \\
\text { Mean } \pm \text { SD }\end{array}$ & $\begin{array}{c}\text { Postoperative } \\
\text { (discharge) } \\
\text { LVEF }(\%) \\
\text { Mean } \pm \text { SD }\end{array}$ & $\begin{array}{c}\text { Postoperative } \\
\text { (after } 3 \mathrm{~m}) \\
(\%) \\
\text { Mean } \pm \text { SD }\end{array}$ & $\begin{array}{c}\text { Preoperative } \\
\text { VS } \\
\text { discharge } \\
\text { p-value }\end{array}$ & $\begin{array}{c}\text { Preoperative } \\
\text { VS after } 3 \mathrm{~m} \\
\text { p value }\end{array}$ & $\begin{array}{c}\text { At } \\
\text { discharge } \\
\text { Vs after } \\
3 \mathrm{~m} \\
\mathrm{p} \text { value } \\
\end{array}$ \\
\hline $\begin{array}{l}\text { Group A } \\
(\mathrm{N}=34)\end{array}$ & $58.3 \pm 11.0$ & $44 \pm 5.1$ & $49.0 \pm 4.7$ & $0.001^{\mathrm{s}}$ & $0,001^{\mathrm{s}}$ & $0.001^{\mathrm{s}}$ \\
\hline $\begin{array}{l}\text { Group B } \\
(\mathrm{n}=28)\end{array}$ & $56.6 \pm 8.4$ & $37.3 \pm 4.8$ & $39.6 \pm 4.7$ & $0.001^{\mathrm{s}}$ & $0.001^{\mathrm{s}}$ & $0.075^{\mathrm{ns}}$ \\
\hline
\end{tabular}

$\mathrm{S}=$ significant, $\mathrm{ns}=$ not significant. 


\section{Discussion:}

This study was compared to those of other studies. Here there was no significant difference of age distribution between two groups. This was similar to other series. ${ }^{4}$ There was no significant difference of cross clump time between two groups this finding were consistent with the report of Wu et al.2000. ${ }^{5}$ In this study incidence of low cardiac output syndrome was less than the other studies. ${ }^{2,6}$ There was significant fall of postoperative LVEF in both groups but there was significantly more fall of postoperative LVEF in group -B. This fall in ejection performance may be due to unfavorable loading conditions imposed by the elimination of low impedance pathway for left ventricle emptying in to left atrium. ${ }^{6}$ In $2002 \mathrm{Wu}$ had shown in his study that the patients of MVR where posterior mitral leaflet were preserved the LV function improved which was due to the continuity of the mitral subvalvular apparatus that may modulate preload adjustment, decreasing afterload increasing contractility of short axis myocardial fibers, maintaining the LV geometry for symmetric and synchronized left ventricular contraction, decreasing posterior left ventricular wall tension. ${ }^{7}$

\section{Conclusion:}

Left ventricular function is better maintained when MVR is done preserving posterior leaflet and subvalvular structure.

\section{Conflict of Interest - None.}

\section{References:}

1. Athanasiou T, Chow A, Rao C, Aziz O Siannis F, Ali A, Darzi A. Preservation of mitral valve apparatus: evidence synthesis and critical reappraisal of surgical techniques. Eur J Cardiothorac Surg 2008; 33: 391-401.

2. Lillehei EW, Levy MJ, Bonnabeau RC. Mitral valve replacement with preservation of papillary muscle and chordae tendinae. J Thorac Cardiovasc Surg 1964; 47(4): 532-543.

3. Sarker R. Outcome of preserving posterior mitral valve leaflet and suvvalvular apparatus during mitral valve replacement. NICVD, Dhaka : Thesis, 2004.

4. Tasmedi O, Katircioglu F, Catav Z, Tezkener T, Kural T, Zorlutuna Y. Clinial result of mitral replacement with or with or without preservation of the posterior mitral leaflet and subvalvular leaflet. J Cardiovasc Surg 1991; 32:509515.

5. Wu ZK., Sun PW, Zhang X, Zong FT, Tong CW, Lu K, et al. Superiority of subvalvilar structure to conventional replacement in severe rheumatic mitral valve disease: a modified technique and result of one year follow up. J Heart Valve Dis 2000; 9(5): 616-622.

6. Rozich JD, Carbello BA, Usher BW, Kratz JM, Bell AE, Zile MR. Mitral valve replacement with or without chordal preservation in patients with chronic mitral regurgitation: Mechanism for difference in postoperative ejection performance, Circulation 1992; 86: 1718-1726.

7. Wu ZK, Sun PW, Zhang X, Zong FT, Tong CW, Lu K, et al. Superiority of Subvalvular structure to conventional replacement in severe rheumatic mitral valve disease: A modified technique and result of one year follow up. $J$ Heart Valve Dis 2000; 9(5): 616- 622. 